\title{
Investigasi Tingkat Kerawanan Gedung Dalam Rangka Implementasi Mitigasi Gempa Bumi di Fakultas Teknik Universitas Mataram
}

\author{
Teti Zubaidah $^{1,2^{*}}$, Rosmaliati ${ }^{1,2}$, Cipta Ramadhani ${ }^{1,2}$, Dwi Ratnasari ${ }^{1,2}$, Made Sutha \\ Yadnya $^{1,2}$, Bulkis Kanata ${ }^{1,2}$, Paniran ${ }^{1,2}$, Abdullah Zainuddin ${ }^{1,2}$, Kenya Damayanti Priyatna ${ }^{1,2}$ \\ ${ }^{1}$ PUI Geomagnetik Universitas Mataram, Mataram, Indonesia. \\ ${ }^{2}$ Jurusan Teknik Elektro, Fakultas Teknik, Universitas Mataram, Mataram, Indonesia.
}

\author{
Article history \\ Received: 08-11-2021 \\ Revised: 17-11-2021 \\ Accepted: 24-11-2021 \\ *Corresponding Author: \\ Teti Zubaidah \\ PUI Geomagnetik Unram, \\ J1. Majapahit No. 62, \\ Mataram, Lombok-Nusa \\ Tenggara Barat, Indonesia \\ Email: \\ tetizubaidah@unram.ac.id
}

\begin{abstract}
After the 2018 Lombok Earthquake, buildings at the Faculty of Engineering, University of Mataram (FT Unram) were severely damaged and there was no comprehensive treatment. Facilities for earthquake mitigation are still minimal and if available they are not designed and placed properly. Some parts of the building have been renovated but appear unfinished, while there were new constructions that have not been investigated regarding their suitability with earthquake mitigation. Anticipating re-occurrence of a major earthquake in Lombok, it is very necessary to implement earthquake mitigation at FT Unram. In this paper, results of vulnerability investigation of each building will be presented including number, type, and level of damages as well as their locations and detailed documentation of each point of damages in form of pictures and photos/videos. Through this activity vulnerabilities of each building can be identified comprehensively, so that appropriate treatments can be carried out, and the safest evacuation route can be planned as well.
\end{abstract}

Keywords: Mitigation; Earthquake; Lombok Earthquake; Vulnerability

Abtrak: Pasca Gempa Lombok 2018, gedung-gedung di Fakultas Teknik Universitas Mataram (FT Unram) mengalami kerusakan cukup parah dan belum ada penanganan yang komprehensif. Fasilitas penunjang mitigasi gempa masih sangat minim dan jikalaupun ada tidak didesain dan ditempatkan dengan baik. Beberapa bagian bangunan telah direnovasi namun tampak belum tuntas, sementara ada pula konstruksi bangunan baru yang belum dikaji secara detail mengenai tingkat kesesuaian terhadap mitigasi gempa. Mengantisipasi terjadinya kembali gempa besar di wilayah Lombok, sangat perlu dilakukan kegiatan implementasi mitigasi gempa Bumi di FT Unram. Dalam tulisan ini akan dipaparkan hasil-hasil investigasi kerawanan setiap gedung berupa jumlah, jenis dan tingkat kerusakan serta lokasi dan dokumentasi detail setiap titik kerusakan dalam bentuk gambar dan foto/video. Dari kegiatan ini diharapkan bahwa kerawanan di setiap gedung dapat teridentifikasi secara menyeluruh, sehingga dapat dilakukan penanganan yang tepat, serta perencanaan jalur evakuasi yang paling aman.

Kata Kunci: : Mitigasi; Gempa Bumi; Gempa Lombok; Kerawanan

\section{PENDAHULUAN}

Fakultas Teknik Universitas Mataram (FT Unram), saat ini memiliki 5 (lima) program studi, yakni Teknik Sipil, Teknik Mesin, Teknik Elektro, Teknik Informatika dan Teknik Arsitektur, dengan jumlah mahasiswa aktif lebih dari 3000. Kegiatan belajar mengajar dan administrasi dilakukan pada 
beberapa gedung yakni Gedung A, Gedung B, Gedung C (C1, C2, C3) dan Gedung D, sebagaimana tampak pada Gambar 1.

Pasca Gempa Lombok 2018, gedung-gedung di lingkungan FT Unram di beberapa bagian mengalami kerusakan yang cukup parah dan belum ada penanganan yang menyeluruh sampai dengan saat ini. Kerusakan yang terlihat cukup parah di Gedung A dan Gedung B, yang di beberapa tempat sempat ditandai (secara semi permanen dengan menggunakan cat/pilox) sesaat setelah terjadinya gempa oleh pihak independen yang melakukan asesmen terhadap gedung-gedung di FT Unram. Namun demikian dengan berlalunya waktu, tanda-tanda tersebut telah banyak hilang atau terhapus ataupun tertutup (karena ada proses pelapisan dinding dengan wall paper untuk mempercantik ruangan) dan ada pula yang sengaja ditutup (barangkali untuk menghilangkan kesan berbahaya). Beberapa bagian Gedung di Teknik Mesin dan Teknik Elektro telah mengalami renovasi sebagian, namun belum dikaji secara mendalam aspek-aspek yang terkait dengan mitigasi bencana.

Dengan semakin bertambahnya jumlah mahasiswa setiap tahunnya, maka pemakaian ruangan dan laboratorium serta sarana-sarana belajar lainnya seperti perpustakaan dan musholla serta kantin juga semakin padat. Hal ini sangat terasa, khususnya sebelum pandemi Covid-19. Pembukaan Prodi Teknik Informatika dan Teknik Arsitektur membuka wacana untuk pengembangan gedung. Untuk mengantisipasi kebutuhan ruangan apabila perkuliahan nanti telah berjalan normal kembali, maka pada saat ini telah dibangun ruang-ruang tambahan di Gedung D. Hal ini tentu saja dapat menjadi sumber masalah tambahan, jika faktor mitigasi bencana gempa Bumi tidak diperhitungkan dalam perencanaannya.

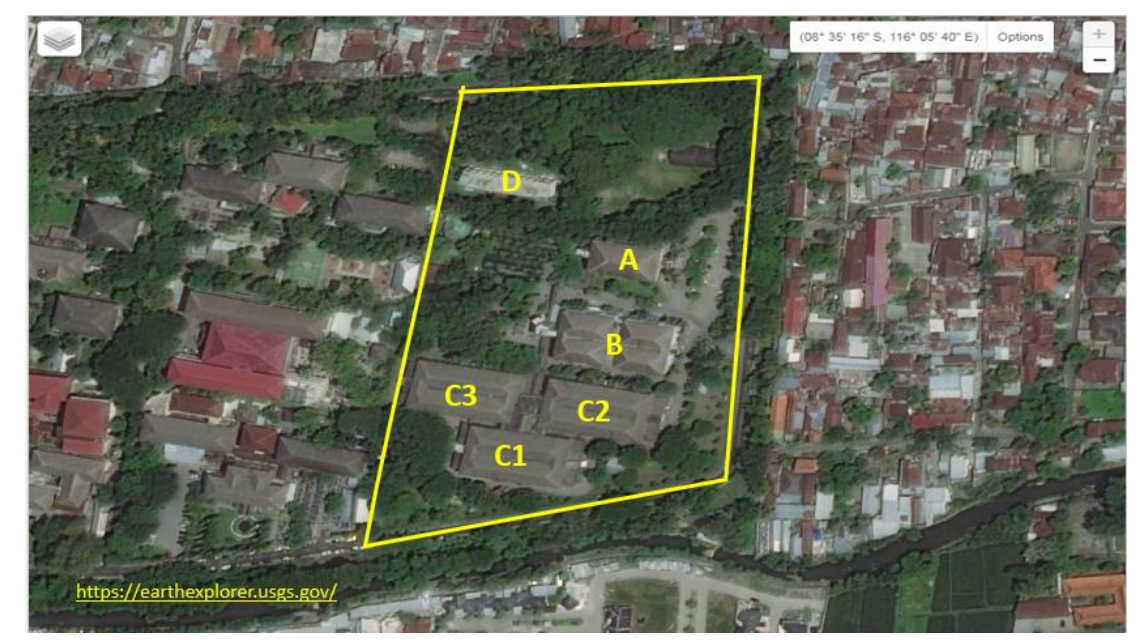

Gambar 1 Fakultas Teknik Unram (dibatasi dengan garis kuning) dan posisi Gedung A, B, C1, C2, C3 dan D.

Ketersediaan sarana yang menunjang mitigasi gempa, seperti rambu-rambu jalur evakuasi dan titik kumpul di lingkungan FT Unram masih minim, hanya terdapat di sebagian gedung dan belum mencakup wilayah tangga (di mana pada bagian ini merupakan jalur yang rawan pada saat evakuasi). Kalaupun terdapat rambu, kebanyakan tidak dirancang dengan fitur khusus (dari segi ukuran dan bahan baku) dan belum diletakkan secara tepat (posisinya terlalu tinggi atau tidak mudah dilihat). Adakalanya juga rambu belum dispesifikasikan secara kompatibel dengan arah penunjuk yang lain, bahkan ada penunjuk lokasi yang diletakkan pada posisi yang dapat menimbulkan kesalahan arah saat evakuasi.

Ketersediaan titik kumpul berikut rambunya juga tidak memadai, dimana saat ini hanya terdapat 2 (dua) titik kumpul yang ditempatkan pada wilayah yang tidak sesuai. Luasan atau volume titik kumpul 
yang tersedia belum pernah dievaluasi secara mendalam, apakah benar-benar dapat menampung seluruh civitas yang sedang beraktifitas di FT Unram, seandainya semua harus dievakuasi pada waktu yang bersamaan. Pembangunan gedung baru dan beberapa fasilitas lain tentu saja juga mengakibatkan semakin berkurangnya ruang terbuka yang dapat dijadikan titik kumpul di lingkungan FT Unram.

Pada ruang-ruang pertemuan di lingkungan FT Unram belum dilengkapi dengan petunjuk keselamatan berupa denah evakuasi. Selama ini juga belum ada petunjuk audio visual yang diputar/ditampilkan apabila ada pertemuan yang melibatkan cukup banyak orang. Tentu saja hal ini sangatlah rawan apabila ada pertemuan dengan banyak tamu-tamu yang baru pertama kali berkunjung ke FT Unram.

Lebih jauh lagi, belum pernah ada sosialisasi yang memadai tentang mitigasi bencana maupun latihan evakuasi untuk civitas akademika FT Unram. Pengetahuan civitas akademika tentang apa sajakah yang harus dilakukan ketika terjadi gempa, ke mana harus melakukan evakuasi, dan apa yang harus dilakukan setelah kejadian gempa sejauh ini masih belum terukur dan belum pernah teruji secara nyata. Selanjutnya kesadaran warga FT Unram akan tingkat risiko di tempat kuliah/tempat kerjanya belum dapat dikatakan menunjukkan tingkat kewaspadaan yang tinggi. Hal ini tercermin dari tidak banyaknya yang menyadari adanya titik-titik rawan di sekitarnya, sehingga belum tentu dapat menghindarinya jika sewaktu-waktu terjadi gempa. Ketiadaan kesadaran semacam ini tentu akan meningkatkan risiko akibat bencana dan kemungkinan jatuhnya korban.

Dalam tulisan ini akan disajikan ulasan mengenai kegiatan pengabdian untuk mengimplementasikan mitigasi gempa Bumi di FT Unram, dengan tujuan mengurangi tingkat kerentanan dan risiko akibat terjadinya bencana gempa Bumi. Kegiatan serupa pernah dilakukan di Universitas Tadulako pasca gempa 2018 oleh Sulendra (2021) denga menerapkan metode "Quick Assessment for Non-Engineered Structures" dan metode asesmen dari World Bank "Level-1. Hasil asesemen dapat mengkategorikan bangunan sejumlah $140(61,4 \%)$ rusak ringan, $69(30,3 \%)$ rusak sedang, dan 19 (8,3\%) rusak berat hingga roboh; namun kegiatan tersebut tidak memetakan secara detail tingkat kerawanan setiap bangunan. Jauh hari sebelum terjadinya gempa Palu, Amir (2012) bahkan telah mengusulkan untuk melakukan RVS (Rapid Visual Screening) terhadap bangunan-banguna di kota Palu berdasarkan FEMA 154. Namun rupanya tindak lanjut dari usulan ini belum terealisasi hingga terjadi gempa 2018, sehingga banyak kerusakan yang tidak terhindarkan. Adeswastoto dan Setiawan (2018) mengusulkan hal yang serupa untuk Gedung Utama Universitas Pahlawan Riau, namun tidak memaparkan hasil evaluasi yang dilakukan. Sari dkk. (2021) telah membuat kemajuan lebih jauh dalam kegiatan mitigasi gempa dan tsunami di kampus Universitas Negeri Padang dengan melakukan perancangan dan visualiasasi infografis shelter Tsunami, agar dapat dimengerti secara mudah oleh khalayak civitas akademika dan telah diujicobakan kepada sejumlah mahasiswa. Mitigasi untuk gedunggedung sekolah telah dilakukan oleh Miyamoto dkk. (2011), dengan menganalisa kondisi kerusakan gedung-gedung sekolah di beberapa tempat di seluruh belahan dunia, termasuk di Indonesia akibat gempa 2007 Sumatera. Ditunjukkan bahwa akibat-akibat fatal dapat dihindarkan dengan melakukan mitigasi jauh-jauh hari sebelum terjadinya kembali gempa. Kesalahan yang terjadi pada gempa sebelumnya dapat dijadikan pelajaran berharga dalam melakukan perbaikan pada struktur gedung untuk menghindari terjadinya kembali kefatalan yang sama.

\section{METODE}

Persoalan prioritas yang akan diselesaikan melalui kegiatan pengabdian adalah: 1). Melakukan peninjauan, inventarisasi dan dokumentasi di lapangan secara langsung; 2). Pembuatan dan pembukuan peta/denah gedung serta infografis; 3). Penentuan lokasi titik-titik kumpul/tempat evakuasi sementara; 4). Perencanaan dan pembuatan label serta rambu-rambu untuk jalur evakuasi dan titik-titik kumpul; 5). 
Pembuatan video tutorial petunjuk keselamatan untuk tempat-tempat pertemuan; 6). Sosialisasi kepada para pemangku kebijakan di FT Unram; 7). Sosialisasi kepada seluruh civitas akademika di lingkungan FT Unram.

Pelaksanaan kegiatan dilakukan dengan metode penerapan langsung hasil-hasil penelitian di lapangan dan dibagi dalam 3 (tiga) tahapan yang keseluruhannya akan diselesaikan dalam jangka waktu 3 (tiga) tahun. Dalam tulisan ini akan dipaparkan kegiatan tahun pertama, yang dilakukan dengan metode sebagai berikut:

\section{Identifikasi}

Yakni secara langsung melakukan kegiatan peninjauan di lapangan, ke seluruh gedung-gedung di lingkungan Fakultas Teknik (Gedung A, Gedung B, Gedung C1-C2-C3, Gedung D, serta areal Kantin, Parkir, Mushola, dan UKM). Dalam kegiatan ini dilakukan pengamatan, pencatatan kondisi secara detail, wawancara dengan penghuni gedung, dan pendokumentasian dengan foto/video.

\section{Pemetaan}

Dibuatkan peta kondisi setiap gedung, yang dapat menunjukkan kondisi riil secara detail untuk masingmasing ruangan pada setiap lantai. Peta disajikan menggunakan software Autocad dan dicetak dalam ukuran kertas A3 (skala 1:100, 1:150, 1:200 maupun 1:300) agar dapat dengan mudah terlihat. Setiap peta dilengkapi dengan legenda dan kode titik-titik kerawanan. Dibuat pula dokumen terpisah sebagai penyerta, berupa foto serta informasi detail mengenai masing-masing titik kerawanan secara lengkap. Pemetaan dilakukan juga dengan bantuan citra satelit untuk menggambarkan keterhubungan antar gedung beserta space kosong yang terdapat di sekelilingnya, yang akan sangat membantu dalam penentuan jalur evakuasi.

\section{HASIL DAN PEMBAHASAN}

Hasil kegiatan yang disajikan dalam tulisan ini berupa contoh peta (sebagaimana terdapat pada Gambar 2) dan dokumen penyertanya berupa foto dan informasi detail masing-masing titik kerawanan (sebagaimana terdapat pada Gambar 3). Selain itu hasil kompilasi dalam bentuk tabulasi jumlah kerusakan serta tingkat kerawanan untuk setiap gedung pada setiap lantainya, yang dirangkum berdasarkan hasil investigasi dan peta yang telah dibuat (sebagaimana terdapat pada Tabel 1).

Tabel 1 Hasil Investigasi Tingkat Kerawanan Gedung FT Unram

\begin{tabular}{|c|c|c|c|c|c|}
\hline \multirow{2}{*}{ Gedung } & \multirow{2}{*}{ Lantai } & \multicolumn{3}{|c|}{ Tingkat Kerawanan } & \multirow{2}{*}{ Jumlah } \\
\hline & & Ringan & Sedang & Berat & \\
\hline \multirow[t]{3}{*}{ A } & 1 & 22 & 7 & 4 & 33 \\
\hline & 2 & 1 & 8 & 4 & 13 \\
\hline & 3 & 5 & 5 & 3 & 13 \\
\hline \multirow[t]{3}{*}{$\mathrm{B}$} & 1 & 7 & 16 & 27 & 50 \\
\hline & 2 & 2 & 30 & 13 & 45 \\
\hline & 3 & 2 & 17 & 2 & 21 \\
\hline \multirow[t]{2}{*}{$\mathrm{C} 1$} & 1 & 8 & - & - & 8 \\
\hline & 2 & 10 & 5 & 2 & 17 \\
\hline \multirow{2}{*}{$\mathrm{C} 2$} & 1 & 10 & 8 & 1 & 19 \\
\hline & 2 & 20 & 11 & 7 & 38 \\
\hline \multirow[t]{2}{*}{$\mathrm{C} 3$} & 1 & 9 & 2 & - & 11 \\
\hline & 2 & 12 & 7 & 1 & 20 \\
\hline \multirow[t]{6}{*}{$\mathrm{D}$} & 1 & 10 & 1 & - & 11 \\
\hline & 2 & 19 & 5 & - & 24 \\
\hline & 3 & 9 & 1 & 1 & 11 \\
\hline & 4 & 16 & 5 & - & 21 \\
\hline & 5 & 3 & - & - & 3 \\
\hline & JUMLAH & 165 & 128 & 65 & 358 \\
\hline
\end{tabular}




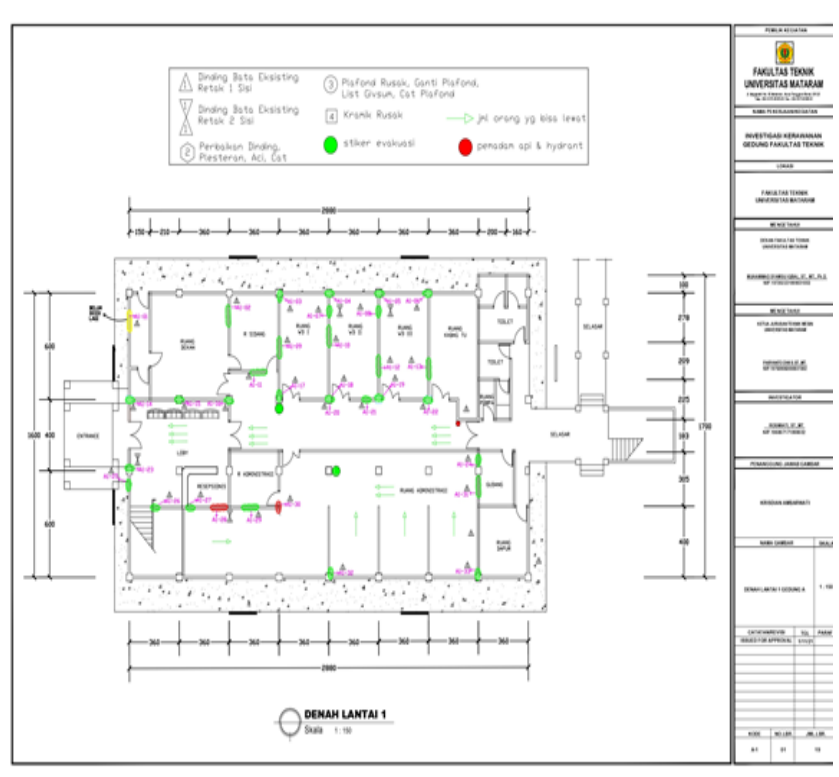

Gambar 2. Hasil pemetaan titik-titik kerawanan pada Gedung A Lantai 1 FT Unram.

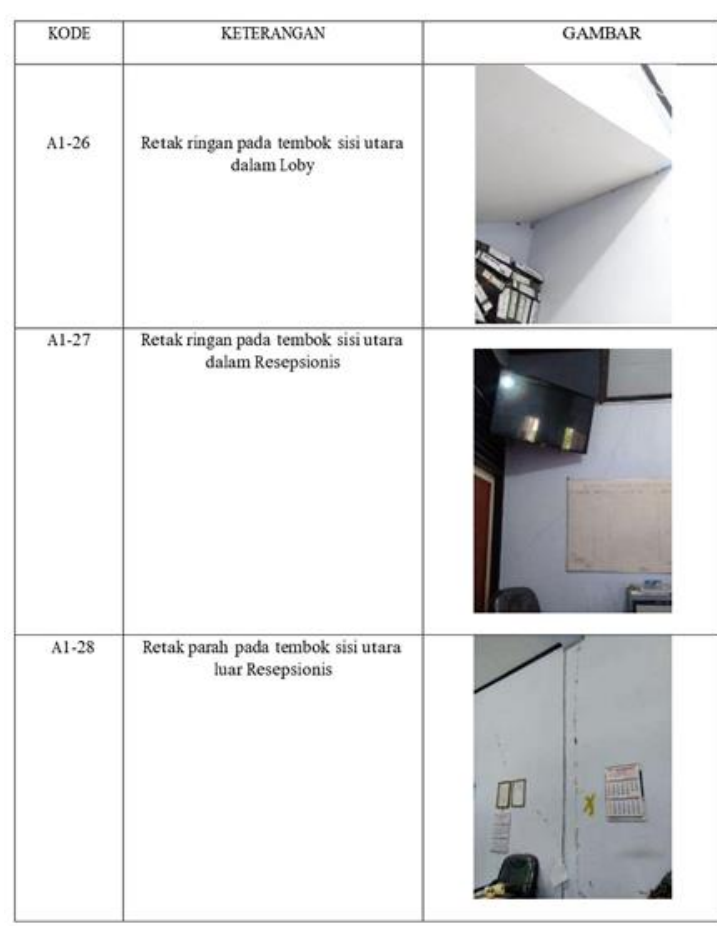

Gambar 3. Contoh informasi penyerta untuk beberapa titik kerawanan pada Gedung A Lantai 1

FT Unram

Data yang ditampilkan pada tulisan ini masih merupakan hasil-hasil awal, dan selanjutnya akan dilakukan kegiatan sosialisasi kepada Pengelola Fakultas dan Prodi, serta akan dihali pula pendapat dari pakar, untuk mendapatkan feedback dan masukan. Revisi hasil akan dilakukan sesuai dengan masukan yang didapat.

\section{KESIMPULAN DAN SARAN}

Kegiatan implementasi mitigasi gempa bumi telah dilakukan di FT Unram, dan pada tahap ini telah dihasilkan pemetaan dan dokumen titik-titik kerawanan. Dengan melihat jumlah titik serta tingkat kerawanannya, maka Gedung B dinilai paling rawan, sedangkan gedung $\mathrm{C}$ dinilai paling aman. Gedung D meskipun baru saja dibangun telah memiliki sejumlah titik kerawanan yang harus mendapakan perhatian.

Saran yang penulis berikan adalah: Setelah selesainya program pengabdian ini Pengelola FT Unram selaku mitra kegiatan diharapkan akan memanfaatkan dengan baik semua luaran yang berhasil dibuat, serta merawat secara berkala ataupun memperbaharui sarana dan prasarana mitigasi menyesuaikan dengan situasi dan kondisi aktual. Selain itu mitra diharapkan akan menggunakan rekomendasi yang diberikan untuk dapat meningkatkan ketahanan civitas akademika di lingkungan FT Unram terhadap bahaya dan ancaman bencana gempa Bumi. Termasuk di antaranya untuk melakukan pelatihan dan simulasi mitigasi gempa Bumi secara berkelanjutan dan terprogram dalam kurikulum pembelajaran di FT Unram.

\section{Ucapan Terima Kasih}

Penulis mengucapkan terima kasih kepada alumni dan mahasiswa yang terlibat aktif dalam kegiatan ini (Alif Adi Prasetya, I Made Wisnu Kusuma Putra, Ramdani Saputra, Muhammad Abulloh Hamzan, Irma Yunihad, Krisdian Ambarwati, Fitrianti Rukmana, Sekar Sari Bintang Solehah, dan 
Khairunnisak). Kegiatan ini didanai oleh PNBP DIPA BLU UNRAM dengan nomor kontrak 1895/UN18.L1/PP/2021 berjudul "Implementasi Mitigasi Gempa Bumi di Fakultas Teknik Universitas Mataram".

\section{DAFTAR PUSTAKA}

Adeswastoto, H. dan Setiawan, B. 2018. Evaluasi Kerentanan Bangunan Gedung Utama Universitas Pahlawan dengan Rapid Visual Screening. Jurnal Teknik Industri Terintegrasi (JUTIN). Vol. 1(2), hal 45-48. https://journal.universitaspahlawan.ac.id/index.php/jutin/article/view/317.

Amir, F. 2012. Evaluasi Kerentanan Bangunan Gedung Terhadap Gempa Bumi dengan Rapid Visual Screening (RVS) Berdasarkan FEMA 154. Infrastruktur. Vol. 2(1), hal 9 - 15. http://jurnal.untad.ac.id/jurnal/index.php/JTSI/article/view/919.

Miyamoto, H. K., Gilani, A. S. J., Wada, A. 2011. Damage mitigation for school buildings in seismically vulnerable regions. International Journal of Disaster Resilience in the Built Environment. Vol. 2(1) hal 8-29. https://www.emerald.com/insight/content/doi/10.1108/17595901111108344/full/html.

Sari, D. M., Afriwan, H., Purnomo, E., Kharisma, M. 2021. Perancangan Infografis Shelter Bangunan di Kawasan Universitas Negeri Padang Sebagai Mitigasi Bencana Alam Gempa dan Tsunami. Gorga: Jurnal Seni Rupa. Vol. 10(02), hal 287-294. https://jurnal.unimed.ac.id/2012/index.php/ gorga/article/view/28098.

Sulendra, I. K. 2021. Asesment Bangunan Gedung di Universitas Tadulako Palu pasca Gempa 28 September 2018 untuk Pelaksanaan Rehabilitasi dan Rekonstruksi. Rekonstruksi Tadulako: Civil Engineering Journal on Research and Development. Vol. 2(1), hal 47-52. https://new.jurnal.untad.ac.id/index.php/ renstra/article/.

Suharjono. 2019. Pengelolaan Keuangan Pondok Pesantren. Jurnal STIE Triguna, Volume 8 Nomor 2: 49-62. 